\title{
Effect of taurine on cell proliferation and apoptosis human lung cancer A549 cells
}

\author{
SHUO TU $^{1 *}$, XIA-LI ZHANG ${ }^{2 *}$, HUI-FANG WAN ${ }^{3}$, YAN-QIN XIA ${ }^{1}$, ZHUO-QI LIU ${ }^{1}$, \\ XIAO-HONG YANG ${ }^{1}$ and FU-SHENG WAN ${ }^{1}$ \\ ${ }^{1}$ Department of Biochemistry and Molecular Biology, Basic Medical College of Nan Chang University; \\ Departments of ${ }^{2}$ Laboratory Animal Science and ${ }^{3}$ Medical Experimental Teaching Center, \\ Nan Chang University, Nanchang, Jiangxi 330006, P.R. China
}

Received December 23, 2015; Accepted November 20, 2017

DOI: $10.3892 / \mathrm{ol} .2018 .8036$

\begin{abstract}
To investigate the effects of taurine on cell proliferation and apoptosis, the human lung cancer A549 cell line and xenograft tumors in nude mice were used. The effects of taurine on cell proliferation and apoptosis were observed at time points of 24, 48 and $72 \mathrm{~h}$ after treatment using an MTT assay to detect the survival rate, and flow cytometry to detect the apoptotic rate. Western blot analysis was performed to examine the levels of p53 upregulated modulator of apoptosis (PUMA), BCL2, apoptosis regulator (Bcl-2) and BCL2-associated X, apoptosis regulator (Bax) in A549 cells. The level of PUMA, Bax and $\mathrm{Bcl}-2$ proteins in the mouse xenograft tumors treated with taurine and/or exogenous PUMA were assessed by immunohistochemistry, with taurine suppressing the proliferation of the human lung cancer A549 cell line in a concentration-dependent manner, and it significantly enhanced the apoptosis rate at all concentrations. Taurine induced the significant upregulation of PUMA and Bax, but led to downregulation of Bcl-2. In comparison to the control group, taurine treatment markedly reduced the volume and weight of A549-derived xenograft tumors in nude mice. Expression of PUMA and Bax were upregulated in the xenograft tumors following taurine treatment, whereas $\mathrm{Bcl}-2$ was downregulated. In addition, the inhibitory effect of taurine and exogenous PUMA on tumor growth was significantly higher than that of a single treatment of taurine or exogenous PUMA. It can therefore be concluded that taurine can inhibit cell proliferation of the human lung cancer A549 cell line and the growth of the xenograft tumors,
\end{abstract}

Correspondence to: Professor Fu-Sheng Wan, Department of Biochemistry and Molecular Biology, Basic Medical College of Nan Chang University, 461 Bayi Road, Nanchang, Jiangxi 330006, P.R. China

E-mail:wanfs01@163.com

*Contributed equally

Key words: taurine, the human lung cancer, apoptosis, p53 upregulated modulator of apoptosis, gene expression whereas PUMA serves an important role in taurine-induced growth suppression.

\section{Introduction}

Lung cancer is one of the most common malignant tumors, currently exhibiting the highest mortality rate worldwide (1). In China, lung cancer has the second highest morbidity rate among the malignant tumors, with the highest morbidity in certain cities (2-4). Overexpression of the anti-apoptosis gene BCL2, apoptosis regulator (BCL2), and insufficient expression of the pro-apoptosis gene BCL2 associated X, apoptosis regulator $(B A X)$, may inhibit cell apoptosis, prolong cell survival and promote cell proliferation; it is thought to be the most common mechanism for the tumorigenesis of lung cancer $(5,6)$. Therefore, examination of the expression of $B C L 2$ and $B A X$ in pre-cancerous lesions could facilitate the early diagnosis of lung cancer.

The amino acid 2-aminoethanesulfonic acid, commonly known as taurine, has a simple chemical structure that contains a thiol group. Taurine accounts for $<0.1 \%$ of total human body weight, and exists in all organs in its free form. Taurine was reported to be an essential nutrient for cats in 1975(7). Subsequent studies have revealed that the endogenous synthesis of taurine in humans is limited and that humans may suffer from taurine deficiency under certain conditions where there is insufficient intake; hence, taurine is considered to be an essential nutrient for humans $(8,9)$. Recent studies have proposed that changes in systemic taurine levels can be used to predict the formation and malignant transformation of certain tumors $(10,11)$. For example, the serum level of taurine was found to be significantly lower in patients with breast cancer than in patients in the high-risk breast cancer group or the healthy control group (7). Thus, taurine is considered a novel biomarker for early diagnosis of breast cancer (10). High levels of taurine were also detected in the urine of patients with non-muscle invasive bladder cancer, indicating that taurine could also serve as a novel indicator for the diagnosis of bladder cancer (11). Taurine has been shown to exert an inhibitory effect on dimethylbenzanthracine-induced breast cancer in rats; it was also demonstrated that taurine could induce apoptosis and suppress proliferation in colorectal and breast cancer cells $(12,13)$. Okamoto et al $(14)$ reported that 
taurine exerted a protective effect against chemical-induced tumorigenesis of liver cancer in male F344 rats, using diethylnitrosamine as the carcinogen and phenobarbital as the tumor promotor. When $\mathrm{S}_{180}$ xenograft tumors in nude mice were treated with taurine, apoptosis was markedly increased: The expression of the anti-apoptotic protein Bcl-2 was reduced, whereas the expression of the pro-apoptotic protein Bax was upregulated (15). Taurine can also downregulate the expression of matrix metalloproteinase-2 and upregulate the expression of $\mathrm{N}$-acetyl galactosaminyl transferase 2, suppressing the potential invasion and metastasis of glioma cells (16).

To the best of our knowledge, the effect of taurine on lung cancer cells has not yet been reported. In this study, the human non-small cell lung cancer A549 cell line was used to investigate the pro-apoptotic and anti-proliferation effects of taurine on lung cancer cells. The underlying molecular mechanism was also elucidated to provide evidence of the potential clinical application of taurine in tumor therapy.

\section{Materials and methods}

Reagents and antibodies. Taurine was purchased from Sigma-Aldrich; Merck KGaA (Darmstadt, Germany). RPMI-1640,Dulbecco's Modified Eagle's Medium(DMEM) and fetal bovine serum (FBS) were purchased from Gibco; Thermo Fisher Scientific, Inc. (Waltham, MA, USA). The anti-p53 upregulated modulator of apoptosis (PUMA) polyclonal antibody (cat. no. 55120-1-AP) was purchased from ProteinTech Group, Inc. (Chicago, IL, USA); the anti-Bcl-2 monoclonal antibody (cat. no. sc-783), anti-Bax monoclonal antibody (cat. no. sc-526), anti- $\beta$-actin monoclonal antibody (cat. no. sc-130300) and anti-HA monoclonal antibody (cat. no. sc-393579) were all purchased from Santa Cruz Biotechnology, Inc. (Dallas, TX, USA). Horseradish peroxidase (HRP)-labeled goat anti-mouse IgG (cat. no. ZDR-5307), HRP-labeled goat anti-rabbit IgG (cat. no. ZDR-5306), trypsin, SDS and TEMED were all purchased from Origene Technologies, Inc. (Beijing, China). Cisplatin (DDP) was purchased from Shandong Qilu Pharmaceutical Co., Ltd. (Jinan, China).

Cell lines and animals. The human non-small cell lung cancer A549 cell line was purchased from the Type Culture Collection of the Chinese Academy of Sciences (Shanghai, China). A total of 40 4-week-old BALB/C nude mice (half from each sex), weighing $20 \mathrm{~g}$ (SPF grade; certificate no. HNASLKJ20121369), were purchased from Hunan SJA Laboratory Animal Co., Ltd. (Hunan, China), and maintained in individually ventilated cages $\left(20-26^{\circ} \mathrm{C}\right.$ and $40-70 \%$ humidity), in the Animal Science Center of Nanchang University (Nanchang, China). The mice were fed with SPF grade aseptic mice feed purchased from Beijing Keao Xieli Feed Co., Ltd. (Beijing, China) and sterilized water, 12/12 h light/dark cycle. All animal experiments were approved by the Ethics Committee of Nanchang University.

Grouping and treatment. The human non-small cell lung cancer cell line A549 were cultured in RPMI-1640 complete culture solution supplemented with $10 \%$ FBS and stored at $37^{\circ} \mathrm{C}$ in a $5 \% \mathrm{CO}_{2}$ incubator. A549 cells at the logarithmic growth phase were randomly divided into 6 groups: Control, taurine $20 \mathrm{mM}$, taurine $40 \mathrm{mM}$, taurine $80 \mathrm{mM}$, taurine $160 \mathrm{mM}$ and the positive control group, DDP $(10 \mathrm{mg} / \mathrm{ml})$. The cells were then treated with the respective agents for 24,48 and $72 \mathrm{~h}$.

MTT assay for cell proliferation. A549 cells at the logarithmic growth phase were collected, and the concentration of the cell suspension was adjusted based on the Trypan blue method. In total, $200 \mu \mathrm{l}$ of cell suspension was added to each well of a 96-well plate, to a final density of 3,000-8,000 cells per well. Each assay point was performed in four replicates, and the empty wells at the edges of the plates were filled with sterile PBS. The cells were cultured at $37^{\circ} \mathrm{C}$ in a $5 \% \mathrm{CO}_{2}$ incubator. The following day, the cells were treated with taurine at the various concentrations or with DDP $10 \mathrm{~g} / \mathrm{ml}$. After $48 \mathrm{~h}$ incubation, $20 \mu \mathrm{l}$ of MTT solution $(5 \mathrm{mg} / \mathrm{ml})$ was added to each well for and incubated for $4 \mathrm{~h}$. The supernatant in each well was then gently aspirated, and $150 \mu$ l dimethyl sulfoxide was added to each well to dissolve the crystals, and the plate was shaken on a horizontal shaker for $10 \mathrm{~min}$. The optical density (OD) at $490 \mathrm{~nm}$ were measured using a microplate reader, and the inhibition ratio was calculated using the following equation: Inhibition ratio $(\%)=(1-$ OD value of the experimental group/OD value of the control group) x100.

Hoechst 33342 staining for cell apoptotic morphology. A549 cells at the logarithmic growth phase were collected and seeded into 12-well plates, at a density such that the adherent cells reached $70-90 \%$ confluence by the following day. The cells were then divided into five groups: Control, taurine $40 \mathrm{mM}$, taurine $80 \mathrm{mM}$, taurine $160 \mathrm{mM}$ and DDP $10 \mathrm{~g} / \mathrm{ml}$, with 3 replicates in each group. The cell lines were treated for $48 \mathrm{~h}$ at $37^{\circ} \mathrm{C}$ in a $5 \% \mathrm{CO}_{2}$ incubator. The medium was then removed, the cells were washed twice with PBS and $500 \mu$ l Hoechst 33342 stain solution $(5 \mu \mathrm{g} / \mathrm{ml})$ was added into each well to completely cover the cells. The cells were then incubated in the dark at $37^{\circ} \mathrm{C}$ in a $5 \% \mathrm{CO}_{2}$ incubator for 20-30 min. Subsequently, the Hoechst 33342 stain was removed, the cells were washed twice with PBS and apoptotic morphology was observed under a fluorescence microscope (x200 magnification) and images were captured. A total of ten random high magnification fields were selected to calculate cell apoptosis ratio as follows: Cell apoptosis ratio $=$ apoptotic cell number/total cell number $\mathrm{x} 100$.

Flow cytometry analysis of apoptosis. Following a $48 \mathrm{~h}$ treatment, as aforementioned, $1-5 \times 10^{5}$ cells were collected and resuspended in $500 \mu \mathrm{l}$ Binding Buffer (Annexin V-FITC/PI double staining cell apoptosis detection kit; Jiangsu Keygen Biotechnology Co., Ltd., Nanjing, China). Annexin V-fluorescein isothiocyanate (FITC; $5 \mu \mathrm{l}$ ) and $5 \mu \mathrm{l}$ propidium iodide (PI) were added successively into the cell suspension, mixed well and incubated for 5-15 min at room temperature in the dark. The cells were then analyzed for apoptotic status using a FACSCalibur flow cytometer with the BD CellQuest ${ }^{\mathrm{TM}}$ Pro Analysis system (version 6.1; BD Biosciences, Franklin Lakes, NJ, USA).

Western blot analysis of expression of PUMA, Bax and Bcl-2. Following the aforementioned $48 \mathrm{~h}$ treatments, A549 cells were collected and total protein was extracted with cell lysis buffer 
(cat. no. P0013; Beyotime Institute of Biotechnology, Haimen, China) and denatured. Standard bovine serum albumin solution was used to produce the standard curve of protein content to measure the concentration of protein. A total of $30 \mu \mathrm{g}$ total protein per lane from each sample was subjected to $10 \%$ SDS-PAGE. Following electrophoresis, protein was transferred to a polyvinylidene fluoride membrane using a current of $330 \mathrm{~mA}$ for $60 \mathrm{~min}$. The membrane was blocked by $1 \%$ bovine serum albumin (cat. no. ST023; Beyotime Institute of Biotechnology) at room temperature for $2 \mathrm{~h}$, and then incubated with specific antibodies against PUMA, Bax or Bcl-2 (1:200) at $4{ }^{\circ} \mathrm{C}$ overnight, followed by incubation with the appropriate HRP-conjugated secondary antibody $(1: 2,000)$ for $1.5 \mathrm{~h}$. The western blots were developed using pierce ${ }^{\mathrm{TM}}$ ECL western blotting substrate (Pierce; Thermo Fisher Scientific, Inc.), and the protein bands analyzed for protein density using Image-Pro Plus 6 software (Media Cybernetics, Inc., Rockville, MD, USA). We used the ratio of the gray value of the target protein to the gray value of the $\beta$-actin as the final result, to produce a semi-quantitative analysis.

Establishment of a xenograft tumor model in nude mice. A549 cells were inoculated subcutaneously in the left and right flanks of the abdomen of 405 -week-old nude mice. Once the diameter of the tumors reached between 2-3 mm, the mice were randomly divided into four groups: i) Control group, treated with $0.2 \mathrm{ml}$ saline was injected at multiple sites inside and around the tumor; ii) taurine treatment group, treated with $0.2 \mathrm{ml}$ taurine solution $(100 \mathrm{mg} / \mathrm{kg})$ injected at multiple sites inside and around the tumor; iii) exogenous PUMA treatment group, treated with $0.2 \mathrm{ml}$ mixture of pCEP4-(HA) $)_{2}$-PUMA plasmid (100 $\mu \mathrm{g}$; Institute of Cancer Research, University of Pittsburgh, Pittsburgh, PA, USA) and liposome (Invitrogen; Thermo Fisher Scientific, Inc.) injected at multiple sites inside and around the tumor which have been sterilized with $75 \%$ alcohol; iv) taurine and exogenous PUMA treatment group (combined treatment group), treated with $0.1 \mathrm{ml}$ taurine solution $(100 \mathrm{mg} / \mathrm{kg})$ and $0.1 \mathrm{ml}$ mixture of pCEP4-(HA) $)_{2}$-PUMA plasmid $(100 \mu \mathrm{g})$ and liposome injected simultaneously at multiple sites inside and around the tumor. The treatment was applied seven times, with an interval of $72 \mathrm{~h}$ between each treatment. The diameter of the tumors was measured every $72 \mathrm{~h}$ for the calculation of tumor volumes, and tumor growth curves were plotted accordingly. The mice were euthanized on day 27 and the tumors were photographed and weighed. The tumor suppression ratio was then calculated as follows: Tumor volume $\left(\mathrm{cm}^{3}\right) \mathrm{V}_{\mathrm{T}}=1 / 2 \mathrm{x}$ a x b $\mathrm{b}^{2}$ ( $\mathrm{a}$ is the longer $\mathrm{arm}, \mathrm{b}$ is the shorter arm); Tumor suppression ratio $(\%)=$ (average tumor weight of control group-average tumor weight of treatment group)/average tumor weight of control group x100.

Immunohistochemical analysis. When the mice were euthanized, the tumors were collected and any blood was washed off with PBS. Immediately following photography, the tumors were fixed with $4 \%$ paraformaldehyde for $24 \mathrm{~h}$ at $4^{\circ} \mathrm{C}$, and examined for expression levels of PUMA, Bax and Bcl-2 by immunohistochemistry. Tissue samples were paraffin embedded, sectioned (3 $\mu \mathrm{m})$, heated at $65^{\circ} \mathrm{C}$ for $2 \mathrm{~h}$, dewaxed with conventional xylene (xylene I for $15 \mathrm{~min}$, the xylene II $15 \mathrm{~min}$ ), and dehydrated with a gradient alcohol series $(100 \%$ ethanol for $2 \mathrm{~min}$,

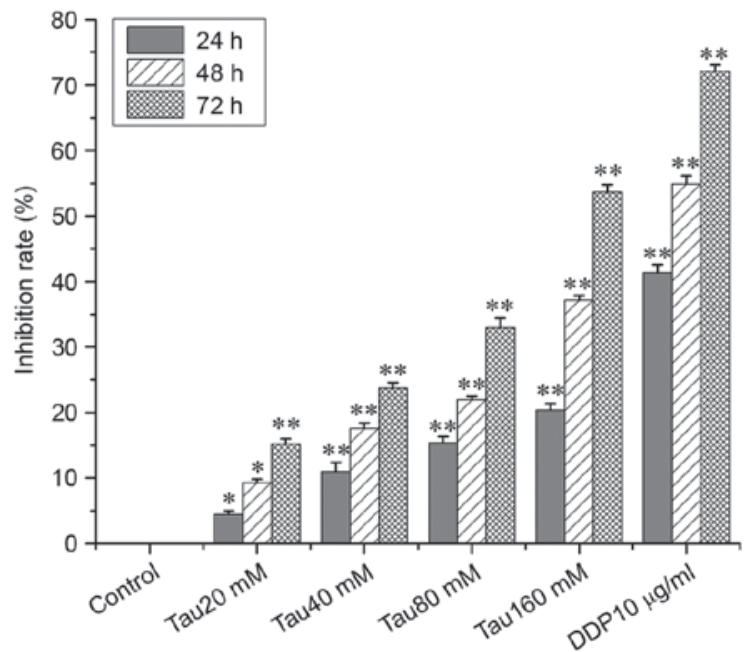

Figure 1. Taurine inhibited proliferation of human non-small cell lung cancer A549 cell line. ${ }^{*} \mathrm{P}<0.05,{ }^{* *} \mathrm{P}<0.01$ vs. control group. Tau, taurine; DDP, cisplatin.

$100 \%$ ethanol for $2 \mathrm{~min}, 95 \%$ ethanol for $2 \mathrm{~min}, 95 \%$ ethanol for $2 \mathrm{~min}, 80 \%$ ethanol for $2 \mathrm{~min}$ then $70 \%$ ethanol for $2 \mathrm{~min}$ ), and then washed 1 time with tap water for $3 \mathrm{~min}$. Antigen retrieval was performed using citric acid buffer $\left(0.01 \mathrm{M}, \mathrm{pH} 6.0,100^{\circ} \mathrm{C}\right)$ and boiled for $20 \mathrm{~min}$ in a microwave oven (wattage, $800 \mathrm{~W}$; time, $20 \mathrm{~min}$ ). Endogenous peroxidase was inactivated with $3 \% \mathrm{H}_{2} \mathrm{O}_{2}$ at $37^{\circ} \mathrm{C}$ for $10 \mathrm{~min}$ in a water bath. Sections were incubated with specific antibodies against PUMA, Bax or Bcl-2 (1:200) at $4^{\circ} \mathrm{C}$ for $6 \mathrm{~h}$, followed by incubation with a horseradish peroxidase-conjugated secondary antibody at $37^{\circ} \mathrm{C}$ for $1 \mathrm{~h}$ (dilution, 1:2,000; cat. no. ZDR-5307) and stained with $3,3 \mathrm{~N}$-diaminobenzidine tertrahydrochloride $(0.5 \mathrm{mg} / \mathrm{ml})$ and hematoxylin $(4 \mathrm{mg} / \mathrm{ml})$ for $5 \mathrm{~min}$ at $25^{\circ} \mathrm{C}$. Under an Olympus BX-41 binocular light microscope (at x40 magnification), images from five fields on each section of two non-consecutive sections of each tumor were captured. The images were then analyzed using HMIAS-2000 image analyzing software (version no. V1.0; Wuhan Qianping Imaging Technology Co., Ltd., Wuhan, China) for automatic calculation of integrated optical density to determine protein expression.

Statistical analysis. SPSS 17.0 statistical software (SPSS, Inc., Chicago, IL, USA) was used to analyze the experimental data, and expressed as the mean \pm standard deviation. One-way analysis of variance followed by LSD post hoc test or unpaired t-test was performed for comparisons between multiple groups, and a Q-test was used to compare two groups among multiple groups. $\mathrm{P}<0.05$ was considered to indicate a statistically significant difference.

\section{Results}

Taurine inhibits the proliferation of the human lung cancer A549 cell line. To investigate the effect of taurine on cell proliferation, A549 cells were treated with various taurine concentrations. As shown in Fig. 1, the inhibitory effect of taurine on the proliferation of A549 cells significantly increased in a time- and concentration-dependent manner when compared with the control group. 

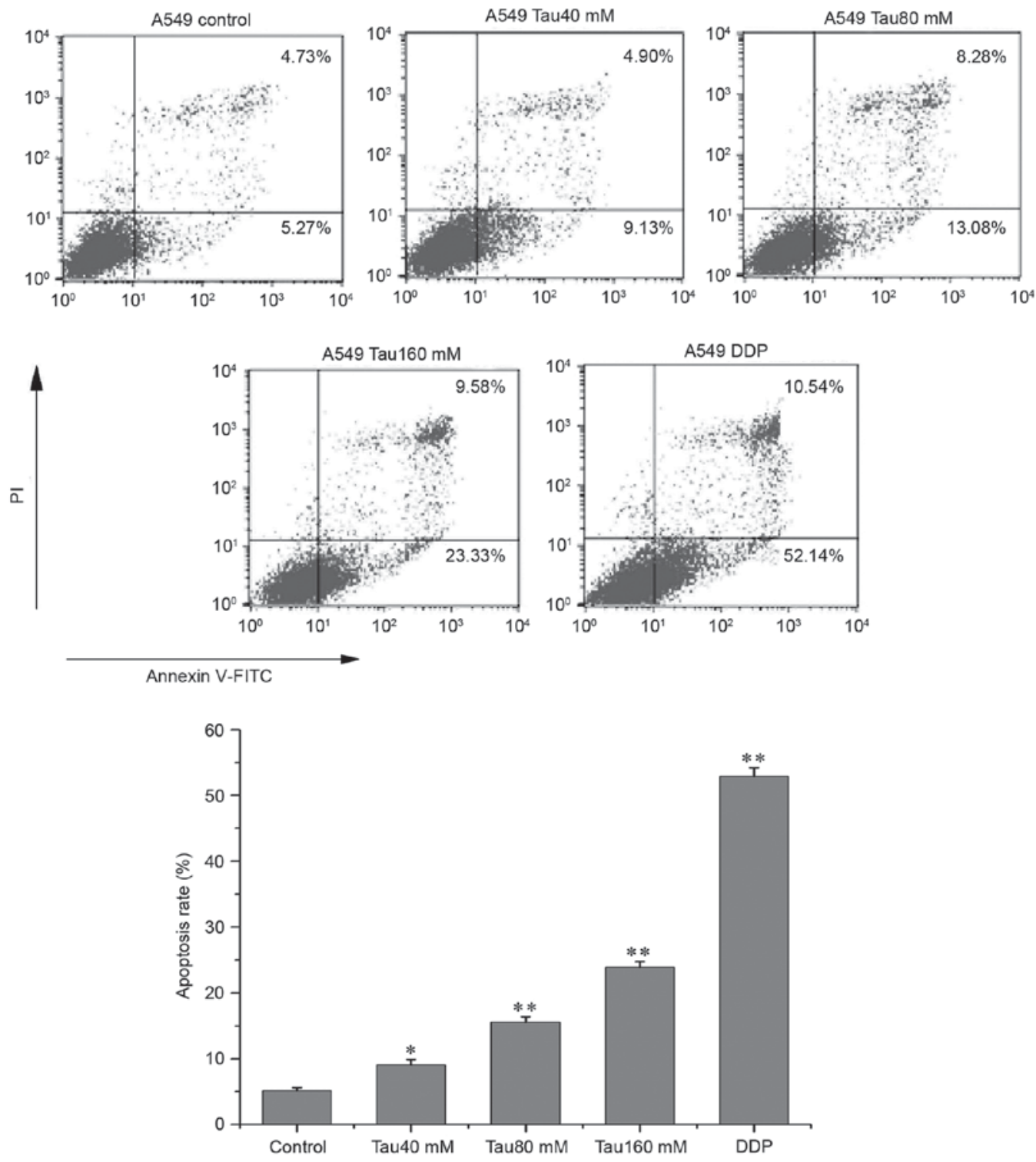

Figure 2. Effect of taurine on the apoptosis of human non-small cell lung cancer A549 cell line. ${ }^{*} \mathrm{P}<0.05,{ }^{* *} \mathrm{P}<0.01$ vs. control group. Tau, taurine; DDP, cisplatin.

Taurine promotes apoptosis in the human lung cancer A549 cell line. A549 cells were treated with different concentrations of taurine (range, $40-160 \mathrm{mM}$ ) for $48 \mathrm{~h}$, and then double-stained with anti-Annexin V-FITC antibody and PI. The apoptosis ratio (Annexin $\mathrm{V}-\mathrm{FITC}^{+} / \mathrm{PI}^{-}$, the lower right quadrant) of A549 cells corresponded with increasing concentrations of taurine (Fig. 2), and the apoptosis ratios of all taurine groups were significantly different when compared with the control group $(\mathrm{P}<0.05, \mathrm{P}<0.01)$. In addition, Hoechst 33342 fluorescence staining revealed that the numbers of apoptotic cells were also increased as taurine concentration increased, and that the number of apoptotic cells were significantly higher than in the control group (Fig. 3; $\mathrm{P}<0.01$ ).

Taurine regulates the expression of PUMA, Bax and Bcl-2 in the human lung cancer A549 cell line. Western blot analysis revealed that the expression of PUMA and Bax was significantly upregulated, whereas that of Bcl-2 was significantly downregulated in A549 cells. This trend continued with increasing concentrations of taurine, compared with the control group (Fig. 4; $\mathrm{P}<0.05$ ). Taurine altered the expression levels of PUMA, Bax and Bcl-2 in a dose-dependent manner.

Taurine suppresses the ectopic growth of lung cancer cell-derived xenograft tumors in nude mice. As shown in Fig. 5, treatment with exogenous PUMA alone, taurine alone and combined treatment with exogenous PUMA and taurine gave an average tumor suppression ratio of $42.94 \pm 1.99,50.09 \pm 2.35$ and $78.52 \pm 1.46 \%$, respectively. These ratios all differed significantly from that of control group $(\mathrm{P}<0.01)$. The average tumor volumes and weights of all treatment groups were significantly different from that of control group $(\mathrm{P}<0.01)$. In addition, the tumor suppression ratio of the combined-treatment group was much higher than that of the taurine or PUMA single-treatment groups, indicating that combined treatment with taurine and exogenous PUMA act synergistically to suppress the growth of xenograft tumors in nude mice.

Taurine regulates the expression of PUMA, Bax and $B c l-2$ in xenograft tumors in nude mice. The results of 


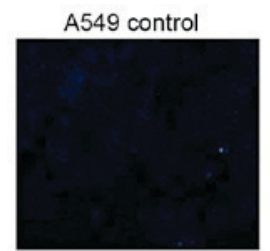
A549 Tau40 mM
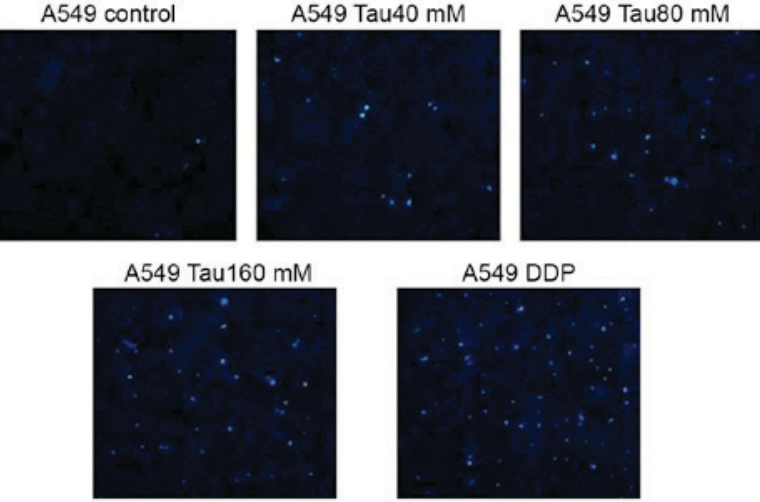

A549 DDP

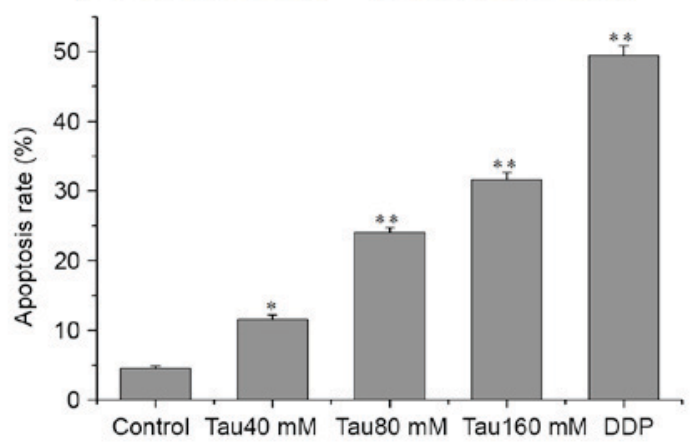

Figure 3. Hoechst 33342 staining for the effect of taurine on the apoptosis of cell line A549 (magnification, $\mathrm{x} 200$ ). ${ }^{*} \mathrm{P}<0.05,{ }^{* *} \mathrm{P}<0.01$ vs. control group. Tau, taurine; DDP, cisplatin.

immunohistochemistry (Figs. 6-8) revealed that the levels of PUMA and Bax were significantly elevated in the cytoplasm of tumor cells treated with taurine, PUMA and taurine and exogenous PUMA, when compared with the control group $(\mathrm{P}<0.01)$. Moreover, the levels of proteins in the cytoplasm were significantly higher in the taurine and exogenous PUMA group, than in the PUMA or taurine single-treatment groups $(\mathrm{P}<0.01)$. Compared with the control group, the level of cytoplasmic Bcl-2 was significantly decreased in the taurine, exogenous PUMA and taurine and exogenous PUMA treatment groups $(\mathrm{P}<0.01)$. In addition, the level of cytoplasmic $\mathrm{Bcl}-2$ was the lowest in the taurine and exogenous PUMA group (Fig. 9), and was significantly different to that of the taurine or PUMA single-treatment groups $(\mathrm{P}<0.01)$.

\section{Discussion}

Taurine is an amino sulfonic acid that naturally exists in the human body. It is an endogenous anti-injury substance, including oxidative stress injury, alcoholic liver injury and injury of endotoxin to myocardium that possesses a wide spectrum of physiological and pharmacological functions, including anti-oxidative activities and modulation of calcium homeostasis $(12,17)$. Taurine has been used for treatment of inflammation, hepatobiliary diseases, cardiovascular diseases (18), diabetes mellitus (19), cataracts (20) and a number of other diseases. Taurine treatment reportedly leads to downregulation of the anti-apoptotic protein Bcl-2 and upregulation of the pro-apoptotic protein Bax in nude mice $S_{180}$ xenograft tumors, as revealed by immunohistochemical analysis (15). This therefore leads to enhanced apoptosis in the xenograft tumors. In addition, taurine can also induce apoptosis in human

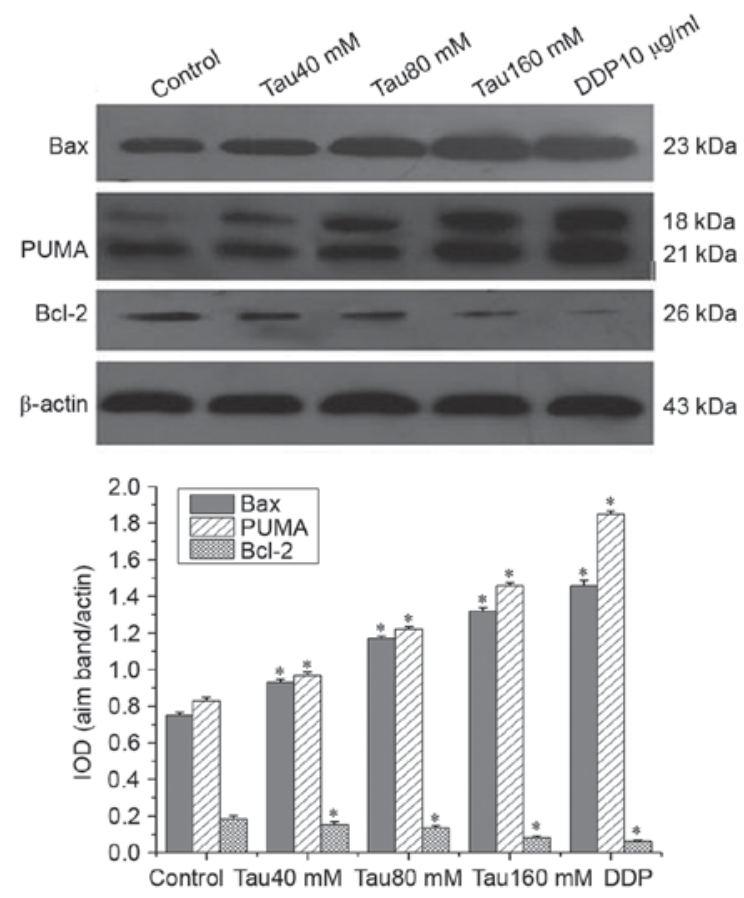

Figure 4. Effect of taurine on the expression of PUMA, Bax and Bcl-2 proteins in human lung cancer A549 cell line. Values are expressed as the mean \pm standard deviation; $n=3$. ${ }^{*} \mathrm{P}<0.05$ vs. control group. Tau, taurine; DDP, cisplatin; Bcl-2, BCL2 apoptosis regulator; Bax, BCL2 associated X, apoptosis regulator; PUMA, p53 upregulated modulator of apoptosis; IOD, integrated option density.

colorectal cancer cells independently of tumor protein p53 (hereafter p53), by upregulating PUMA (12). However, studies on the effect of taurine on lung cancer are limited. Hence, this study focused on the effect of taurine on the proliferation and apoptosis of the human lung cancer A549 cell line.

The in vitro experiments of the present study revealed that taurine at a concentration of $20-160 \mathrm{mmol} / \mathrm{l}$ could inhibit the proliferation of and promote apoptosis in A549 cells, and that the effect was dose- and time-dependent (Figs. 1-3). With increasing concentration of taurine, the expression of PUMA and Bax was significantly upregulated, whereas that of Bcl-2 was downregulated (Fig. 4). The regulatory effect of taurine on the expression of PUMA, Bax and Bcl-2 in A549 cells was dose-dependent. This dose-dependent activity may represent the major mechanism for the pro-apoptotic and anti-proliferative effect of taurine on A549 cells.

Tumorigenesis is a multi-factorial and multi-stage process, whereby the activation of oncogenes or loss of tumor suppressor genes leads to dysregulation of cell proliferation, differentiation and apoptosis. Studies have shown that PUMA affects cell proliferation and induces apoptosis more effectively than p53, meaning that the administration of exogenous PUMA may represent a promising method of tumor therapy $(21,22)$. The ectopic expression of PUMA has been demonstrated to effectively suppress the proliferation of A549 lung cancer cells (23).

In the present study, pCEP4-(HA) $)_{2}$-PUMA recombinant plasmids were injected into the A549 cell-derived xenograft tumors in nude mice to investigate the effect of PUMA on taurine treatment for A549-derived xenograft tumors. The results of this treatment indicated that taurine exerted a strong inhibitory effect on the growth of A549 cell-derived xenograft 
A

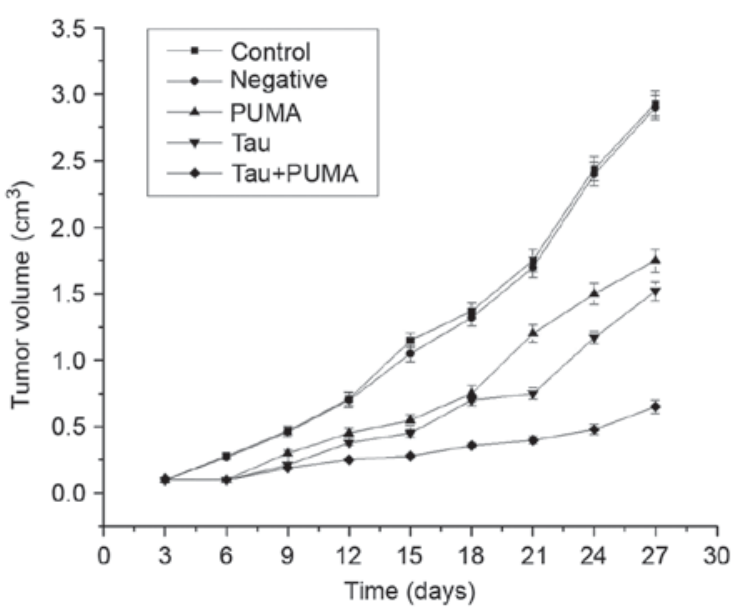

B

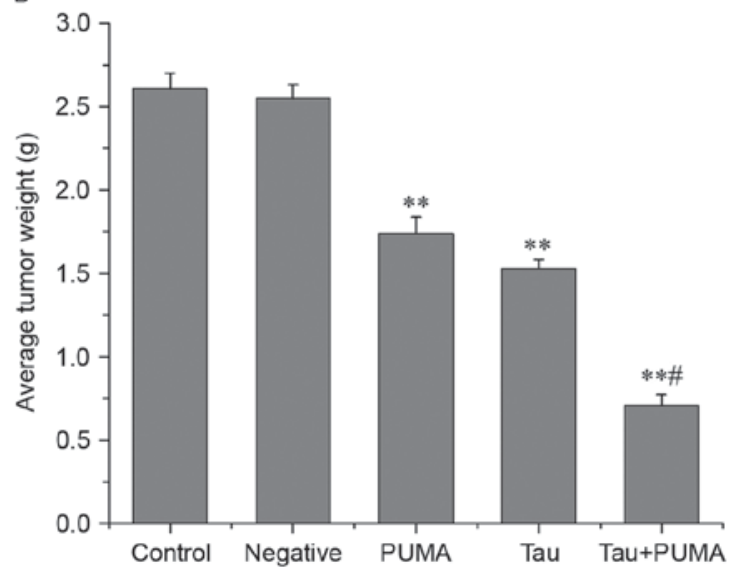

$\mathrm{C}$

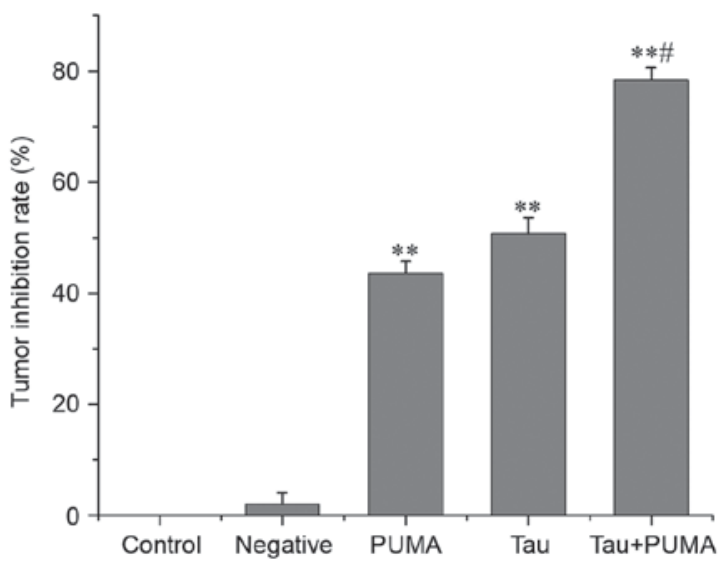

Figure 5. Suppressive effect of taurine and PUMA expression on the growth of lung cancer A549 cell-derived xenograft tumors in nude mice. (A) The growth curve of tumor in nude mice bearing human non-small cell lung cancer A549 cell xenografts. (B) Tumors in nude mice bearing human non-small cell lung cancer A549 cells xenografts. (C) The tumor inhibition rate following 27 days of treatment. Values are expressed as the mean $\pm \mathrm{SD} ; \mathrm{n}=5$. $^{* *} \mathrm{P}<0.01 \mathrm{vs}$. negative or control; ${ }^{\mathrm{P}} \mathrm{P}<0.05$ vs. the PUMA or taurine group. Tau, taurine; PUMA, p53 upregulated modulator of apoptosis.

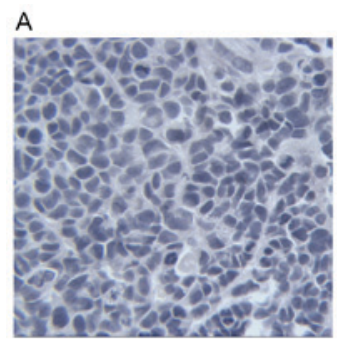

D

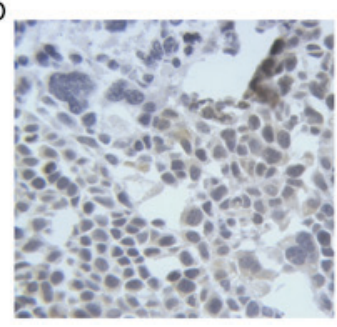

B

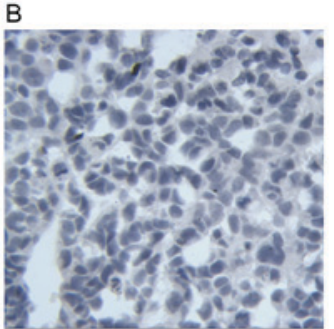

C

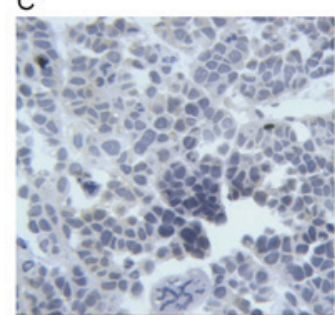

$\mathrm{E}$

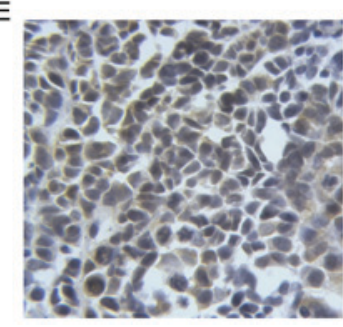

Figure 6. Taurine alters expression of PUMA in lung cancer A549 cell-derived xenograft tumors in nude mice (magnification, x400). (A) Control; (B) negative; (C) exogenous PUMA; (D) taurine; (E) taurine and exogenous PUMA. Tau, taurine; PUMA, p53 upregulated modulator of apoptosis.

tumors in nude mice (Fig. 5). In addition, the treatment with taurine and PUMA combined exerted a better therapeutic effect than the individual treatment group of taurine and exogenous PUMA on the xenograft tumors in terms of suppression of tumor growth, upregulation of PUMA and Bax and downregulation of Bcl-2. The potency of the combined treatment was much greater than each single treatment with taurine or PUMA $(\mathrm{P}<0.05)$. Therefore, PUMA serves a critical role in 

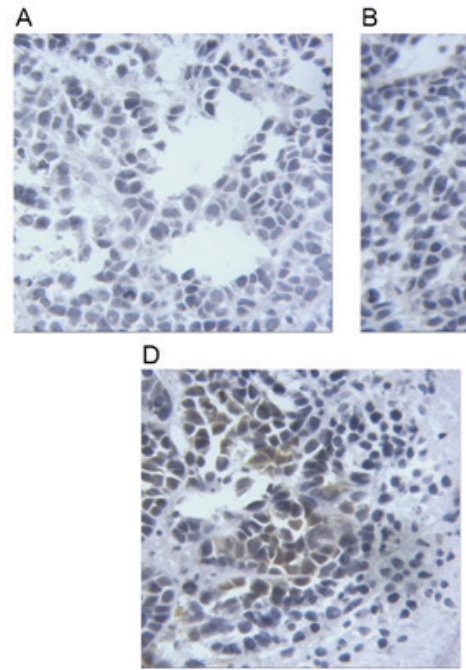

B

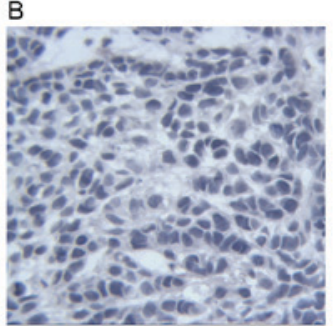

C

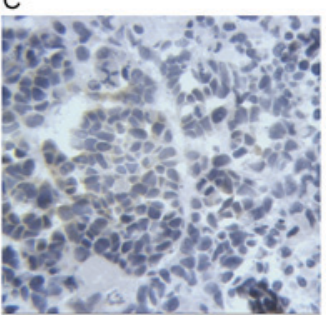

E

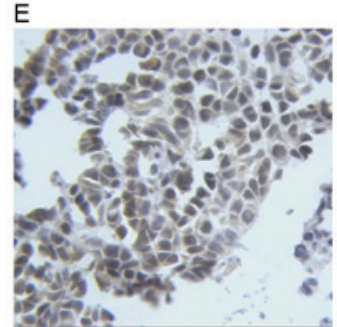

Figure 7. Taurine alters expression of Bax in lung cancer A549 cell-derived xenograft tumors in nude mice (magnification, x400). (A) Control; (B) negative; (C) exogenous PUMA; (D) taurine; (E) taurine and exogenous PUMA. Tau, taurine; Bax, BCL2 associated X, apoptosis regulator.

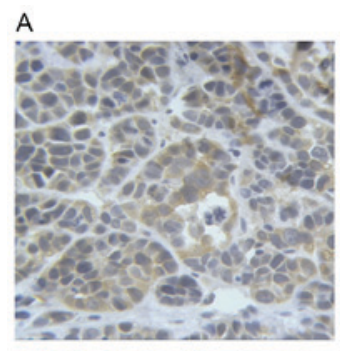

D

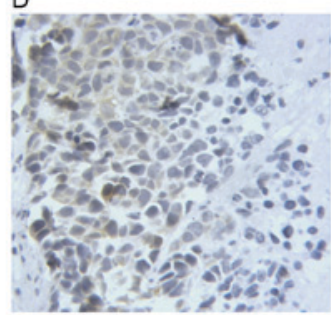

B

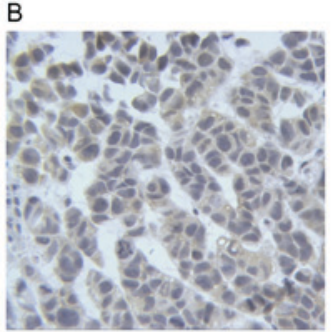

$\mathrm{E}$

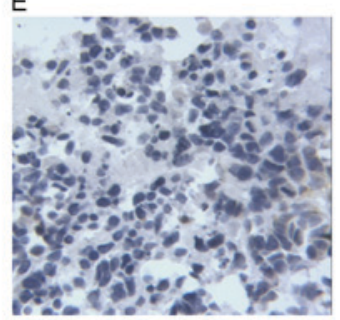

Figure 8. Taurine alters the expression of Bcl-2 in A549 lung cancer cell-derived xenograft tumors in nude mice (magnification, $\mathrm{x} 400$ ). (A) Control; (B) negative; (C) exogenous PUMA; (D) taurine; (E) taurine and exogenous PUMA. Tau, taurine; PUMA, p53 upregulated modulator of apoptosis; Bcl-2, BCL2, apoptosis regulator.

the action of taurine against lung cancer, and may represent a novel target for gene therapy in lung cancer.

PUMA is a member of BH3-only family protein, belonging to the Bcl-2 superfamily. PUMA contains a BH3 domain, which binds to anti-apoptotic proteins, including $\mathrm{Bcl}-2$, Bcl-extra large (Bcl-xL), Bcl-2-like protein 2, induced myeloid leukemia cell differentiation protein $\mathrm{Mcl}-1$ and $\mathrm{Bcl}-2$-related protein A1 (24), exerting potent anti-apoptotic functions. PUMA can enhance mitochondrial membrane permeability and release pro-apoptotic factors to induce cell apoptosis by the following mechanisms: i) PUMA binds to the anti-apoptotic molecule $\mathrm{Bcl}-2 / \mathrm{Bcl}-\mathrm{xL}$ on the mitochondrial membrane to abolish their inhibitory effect on the pro-apoptotic Bax/Bcl-2 homologous antagonist/killer (Bak) dimer; ii) PUMA binds directly to the Bax/Bak dimer on the mitochondrial membrane, inducing a conformational change that leads to their translocation from the cytoplasm to mitochondrial outer membrane and oligomerization, so as to alter the original 'membrane

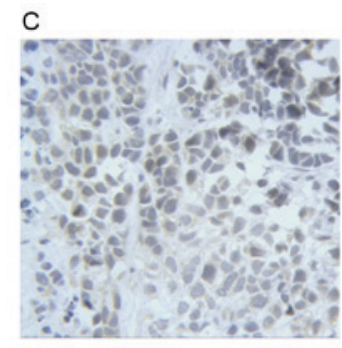


channel protein'; iii) PUMA binds to Bcl-xL in the p53/Bcl-xL complex, releasing p53 and further activating Bax (25-27).

The mechanism of the antitumor effect of taurine is associated with its ability to boost anti-oxidatitive capacity, promote immunity, enhance synergy with chemotherapeutic agents and reduce chemotherapeutic toxicity (28). To protect cells from oxidative injury and promote tumor cell apoptosis, taurine can enhance the anti-oxidative capacity of the body $(28,29)$. Taurine can upregulate the activity of superoxide dismutase, glutathione peroxidase and hydrogen peroxidase, thereby reducing the levels of reactive oxygen species and suppressing the growth of tumor cells (30). The combined use of taurine and the chemotherapeutic agent cisplatin enhanced the antitumor effect of DDP (31), and also activated caspase-3, -6, -7 and -9, activating of the mitochondrial apoptotic pathway. Moreover, Abd-Rabou et al (32) found that taurine in combination with curcumin could enhance immunity in and induce lysis of Huh-7 tumor cells. The results of the present study is consistent with that of a previous publication (33), and reinforces the finding that taurine can upregulate the expression of the pro-apoptotic proteins PUMA and Bax, downregulate the expression of the anti-apoptotic protein $\mathrm{Bcl}-2$, and increase the ratio of $\mathrm{Bax} / \mathrm{Bcl}-2$, thus promoting apoptosis.

In conclusion, taurine can inhibit the proliferation of human lung cancer cells A549 and the growth of transplanted tumors in nude mice, and promote the apoptosis of A549 cells by increasing the protein level of PUMA, Bax and decreasing the protein level of Bcl-2. In nude mice transplanted tumors, PUMA serves a critical role in the action of taurine against lung cancer, and may represent a novel target for gene therapy in lung cancer.

\section{Acknowledgements}

The present study was supported by a grant from the National Natural Science Foundation of China (grant no. 81360032) and the Natural Science Foundation of Jiangxi Province (grant no. 20161BAB205206).

\section{Competing interests}

The authors declare that they have no competing interests.

\section{References}

1. Shi L, Xu ZZ, Wu G, Chen XT, Huang YY, Wang YJ, Jiang WQ and Bin Ke: Up-regulation of miR-146a increases the sensitivity of non-small cell lung cancer to DDP by downregulating cyclin J. BMC Cancer 17: 138, 2017.

2. Rouibaa F, Bakkar M, Seddik H, Addioui T, Filali FZ, Akka R, Desla $\mathrm{H}$ and Aourarh A: Interest of expandable metallic stents in the management of colonic tumor occlusion: Experience of a Moroccan hospital. Pan Afr Med J 2: 245-269, 2013.

3. Watanabe A, Taniguchi F, Izawa M, Suou K, Uegaki T, Takai E, Terakawa $\mathrm{N}$ and Harada T: The role of survivin in the resistance of endometriotic stromal cells to drug-induced apoposis. Hum Reprod 24: 3172-3179, 2009.

4. Zaffaroni N, Costa A, Pennati M, De Marco C, Affini E, Madeo M, Erdas R, Cabras A, Kusamura S, Baratti D, et al: Survivin is highly expressed and promotes cell survival in malignant peritoneal mesothelioma. Cell Oncol 29: 453-466, 2007.

5. Meng J, Fang B, Liao Y, Chresta CM, Smith PD and Roth JA: Apoptosis induction by MEK inhibition in human lung cancer cells is mediated by Bim. PLoS One 5: e13026, 2010.

6. Perez BA, Ghafoori AP, Lee CL, Johnston SM, Li Y, Moroshek JG, Ma Y, Mukherjee S, Kim Y, Badea CT and Kirsch DG: Assessing the radiation response of lung cancer with different gene mutations using genetically engineered mice. Front Oncol 3: 72, 2013
7. Hayes KC, Carey RE and Schmidt SY: Retinal degeneration associated with taurine deficiency in the cat. Science 188: 949-951, 1975.

8. Huxtable RJ: Physiological action of taurine. Physiol Rev 72: 101-163, 1992.

9. Han XB: Human condition essential nutrients-taurine. Foreign Med (Hygienic Branch): 129-132, 1987.

10. El Agouza IM, Eissa SS, El Houseini MM, El-Nashar DE and Abd El Hameed OM: taurine: A novel tumor marker for enhanced detection of breast cancer among female patients. Angiogenesis 14: 321-330, 2011.

11. Srivastava S, Roy R, Singh S, Kumar P, Dalela D, Sankhwar SN, Goel A and Sonkar AA: Taurine-a possible fingerprint biomarker in non-muscle invasive bladder cancer: A pilot study by $1 \mathrm{H} \mathrm{NMR}$ spectroscopy. Cancer Biomark 6: 11-20, 2010.

12. Zhang X, Tu S, Wang Y, Xu B and Wan F: The mechanism of taurine-induced apoptosis in human colon cancer cells. Acta Biochim Biophys Sin (Shanghai) 46: 261-272, 2014.

13. Zhang X, Lu H, Wang Y, Liu C, Zhu W, Zheng S and Wan F: Taurine induces apoptosis of breast cancer cells by regulating apoptosis-related proteins of mitochondria. Int J Mol Med 35: 218-226, 2015.

14. Okamoto K, Sugie S, Ohnishi M, Makita H, Kawamori T, Watanabe T, Tanaka T and Mori H: Chemopreventive effects of taurine on diethylnitrosamine and phenobarbital-induced hepatocarcinogenesis in male F344 rats. Jpn J Cancer Res 87: 30-36, 1996.

15. Wang HR: Experimental study of the effect of taurine on sarcoma $180\left(\mathrm{~S}_{180}\right)$ in mices. PhD dissertation, Qingdao University, Qingdao, 2008.

16. Neary PM, Hallihan P, Wang JH, Pfirrmann RW, BouchierHayes DJ and Redmond HP: The evolving role of taurolidine in cancer therapy. Ann Surg Oncol 17: 1135-1143, 2010.

17. Schaffer SW, Jong CJ, Ito T and Azuma J: Effect of taurine on ischemia-reperfusion injury. Amino Acids 46: 21-30, 2014.

18. Yin Y, Wen K, Wu Y, Kang Y and Lou J: Inhibition of sodium current by taurine magnesium coordination compound prevents cesium chloride-induced arrhythmias. Bio Trace Elem Res 146: 192-198, 2012.

19. El Zahraa Z, EI Ashry F, Mahmoud MF, EI Maraghy NN and Ahmed AF: Effect of Cordyceps sinensis and taurine either alone or in combination on streptozotocin induced diabetes. Food Chem Toxicol 50: 1159-1165, 2012.

20. Son HY, Kim H and H Kwon Y: Taurine prevents oxidative damage of high glucose-induced cataractogenesis in isolated rat lenses. J Nutr Sci Vitaminol (Tokyo) 53: 324-330, 2007.

21. Sun Q, Sakaida T, Yue W, Gollin SM and Yu J: Chemosensitization of head and neck cancer cells by PUMA. Mol Cancer Ther 6: 3180-3188, 2007.

22. Chen D, Wei L, Yu J and Zhang L: Regorafenib inhibits colorectal tumor growth through PUMA-mediated apoptosis. Clin Cancer Res 20: 3472-3484, 2014.

23. Liu CJ, Zhang XL, Luo DY, Zhu WF, Wan HF, Yang JP, Yang XJ and Wan FS: Exogenous p53 upregulated modulator of apoptosis (PUMA) decreases growth of lung cancer A549 cells. Asian Pac J Cancer Prev 16: 741-746, 2015.

24. Yee KS and Vousden KH: Contribution of membrane localization to the apoptotic activity of PUMA. Apoptosis 13: 87-95, 2008.

25. Letai A: Puma strikes Bax. J Cell Biol 185: 189-191, 2009.

26. Adams JM and Cory S: The Bcl-2 apoptotic switch in cancer development and therapy. Oncogene 29: 1324-1337, 2007.

27. Schuler M and Green DR: Mechanisms of p53-dependent apoptosis. Biochem Soc Trans 29: 684-688, 2001.

28. Mates JM, Segura JA, Alonso FJ and Marquez J: Sulphurcontaining non enzymatic antioxidants: Therapeutic tools against cancer. Front Biosci (Schol Ed) 4: 722-748, 2012.

29. Das J, Ghosh J, Manna P and Sil PC: Taurine suppresses doxorubicin-triggered oxidative stress and cardiac apoptosis in rat via up-regulation of PI3-K/Akt and inhibition of p53, p38-JNK. Biochem Pharmacol 81: 891-909, 2011.

30. Yu J and Kim AK: Effect of taurine on antioxidant enzyme system in B16F10 melanoma cells. Adv Exp Med Biol 643: 491-499, 2009.

31. Kim T and Kim AK: Taurine enhances anticancer activity of cisplatin in human cervical cancer cells. Adv Exp Med Biol 776: 189-198, 2013.

32. Abd-Rabou AA, Zoheir KM and Ahmed HH: Potential impact of curcumin and taurine on human hepatoma cells using Huh-7 cell line. Clin Biochem 45: 1519-1521, 2012.

33. Zhang X, Sheng J, Zhang C and Zhao F: Taurine induces apoptosis in pulmonary artery smooth muscle cells. Zhongguo Zhong Yao Za Zhi 37: 654-657, 2012 (In Chinese).

This work is licensed under a Creative Commons Attribution-NonCommercial-NoDerivatives 4.0 International (CC BY-NC-ND 4.0) License. 